\title{
Exploring the Adverse Effects of CAR-T Therapy: A Cases Report of Potential MINOCA in CAR-T
}

\author{
Danielle Verghese, PGY-1 \\ Thomas Jefferson University, danielle.verghese@jefferson.edu
}

Adam Binder, MD

Thomas Jefferson Univeristy, adam.binder@jefferson.edu

Colin Thomas, MD

Thomas Jefferson University, colin.thomas@jefferson.edu

Follow this and additional works at: https://jdc.jefferson.edu/tmf

Part of the Internal Medicine Commons

Let us know how access to this document benefits you

\section{Recommended Citation}

Verghese, PGY-1, Danielle; Binder, MD, Adam; and Thomas, MD, Colin (2020) "Exploring the Adverse Effects of CAR-T Therapy: A Cases Report of Potential MINOCA in CAR-T," The Medicine Forum: Vol. 21 , Article 11.

DOI: https://doi.org/10.29046/TMF.021.1.010

Available at: https://jdc.jefferson.edu/tmf/vol21/iss1/11

This Article is brought to you for free and open access by the Jefferson Digital Commons. The Jefferson Digital Commons is a service of Thomas Jefferson University's Center for Teaching and Learning (CTL). The Commons is a showcase for Jefferson books and journals, peer-reviewed scholarly publications, unique historical collections from the University archives, and teaching tools. The Jefferson Digital Commons allows researchers and interested readers anywhere in the world to learn about and keep up to date with Jefferson scholarship. This article has been accepted for inclusion in The Medicine Forum by an authorized administrator of the Jefferson Digital Commons. For more information, please contact: JeffersonDigitalCommons@jefferson.edu. 


\title{
Exploring the Adverse Effects of CAR-T Therapy: A Case Report of Potential MINOCA in CAR-T
}

\author{
Danielle Verghese, PGY-1, Adam Binder, MD, Colin Thomas, MD
}

\section{INTRODUCTION}

The discovery and application of Chimeric Antigen Receptor T-Cell Therapy (CAR-T) has marked a new era in cancer treatment. CAR-T is a novel therapy with a relatively small treatment population, and we have yet to identify the full spectrum of its adverse effects. ${ }^{1}$ There are well-established approaches to the most common adverse effects, principally cytokine release syndrome (CRS), but there is limited literature discussing the nature of cardiotoxicity in CAR-T, much less its mechanism or management. 2.3 This case study discusses the development of myocardial infarction with no obstructive coronary atherosclerosis (MINOCA) in a patient treated with CAR-T.

\section{CASE PRESENTATION}

A 48-year-old man with a history of Stage IV Diffuse Large B-Cell Lymphoma refractory to R-CHOP alternating with high-dose methotrexate and cytarabine, craniospinal irradiation, and haploidentical stem cell transplant, underwent CD 19-directed CAR-T. His post-treatment course was complicated by marrow aplasia and infection, but he ultimately responded to therapy and achieved complete remission.

Five months after undergoing CAR-T, the patient presented with persistent malaise and vague abdominal pain. Initial assessment found him to be cachectic and frail, and he was admitted for further investigation of failure to thrive (FTT). An extensive workup of endocrine, metabolic, and infectious causes of FTT was unrevealing. Labs showed stable neutropenia (ANC 0.4) and anemia ( Hgb 9.7) with no evidence of adrenal insufficiency, thyroid dysfunction, vitamin deficiencies, nor bacterial, viral, or fungal infections. EGD did not reveal any significant gastrointestinal pathology, only patches of chronic, mild inflammation.

On the sixth day of hospitalization, the patient reported left shoulder pain. Telemetry showed an acute increase in heart rate, from a baseline sinus tachycardia of 100-110 bpm to 130-140 bpm. EKG revealed new inferior ST segment elevations. Echocardiography identified newly depressed ejection fraction (45\%) and basal to mid-anterior and anteroseptal wall motion abnormalities, where previous studies had shown normal EF and no segmental wall motion abnormalities. High-sensitivity troponins were elevated and continued to rise from $344 \mathrm{ng} / \mathrm{L}$ followed by $366 \mathrm{ng} / \mathrm{L}$ in the setting of normal renal function. Subsequent cardiac catheterization revealed no obstructive coronary artery disease. Altogether, the evidence for myocardial injury in the absence of obstructive coronary artery disease culminated in a diagnosis of MINOCA.

A multi-disciplinary team including Cardiology and Hematology-Oncology reviewed possible etiologies of cardiac injury. Although the patient had previously received doxorubicin chemotherapy (total of $229 \mathrm{mg}, 20$ months prior to this admission), the acute onset of ST elevations and dynamic troponins were atypical for anthracycline-induced cardiomyopathy. ${ }^{4}$ Similarly, the presentation was not typical for stress-induced cardiomyopathy, especially in the absence of an acute trigge. ${ }^{5}$

The constellation of cardiac findings was attributed to myocarditis, but the underlying cause remained unclear. The patient was not taking any medications commonly associated with myocarditis. Infectious workup was negative including blood cultures, urine cultures, influenza A and B, respiratory pathogen panel, EBV, CMV, tuberculosis and aspergillus testing. Of note, testing for coxsackie A and B, HIV, and HSV was not performed. Previous reports have posited a CRS-mediated mechanism of cardiac injury in CAR-T, but CRS typically peaks days after treatment, and would be uncommon months after CAR-T infusion. ${ }^{6}$ Another proposed mechanism considers off-target cross-reactivity, leading to an autoimmune myocarditis. ${ }^{6}$ The next best steps to workup myocarditis would have been further infectious testing, cardiac MRI, endomyocardial biopsy, but these were deferred as the patient was high-risk for invasive procedures and the findings were unlikely to change clinical management.

Besides myocarditis, other etiologies of MINOCA include coronary vasospasm, coronary microvascular dysfunction, and thrombophilia?. These were not further investigated during the patient's hospitalization. 
The Medicine Forum, Vol. 21 [2020], Art. 11

\section{DISCUSSION}

CAR-T is a novel therapy with a relatively small treatment population, and we have yet to uncover the full spectrum of its effects. This case illustrates the potential for MINOCA as a result of CAR-T-induced myocarditis. Other possible etiologies of MINOCA include coronary vasospasm and coronary microvascular dysfunction, but there is no available literature on these pathologies in CAR-T. Identifying similar cases will allow for further characterization of susceptible patient populations, underlying mechanisms, and preventative strategies.

\section{REFERENCES}

1. Hirayama, A. V., \& Turtle, C. J. (2019). Toxicities of CD19 CAR-T cell immunotherapy. American Journal of Hematology, 94(S1), S42-S49. doi: 10.1002/ajh.25445

2. Schuster, S. J., Bishop, M. R., Tam, C. S., Waller, E. K., Borchmann, P., Mcguirk, Jp. P., ... Maziarz, R. T. (2019). Tisangenlecleucel in Adult Relapsed or Refractory Diffuse Large B-Cell Lymphoma. New England Journal of Medicine, 380(1), 45-56. doi: 10.1056/nejmoa1804980

3. Brudno, J. N., \& Kochenderfer, J. N. (2016). Toxicities of chimeric antigen receptor T cells: recognition and management. Blood, 127(26), 3321-3330 doi:10.1182/blood-2016-04-703751

4. McGowan, J. V., Chung, R., Maulik, A., Piotrowska, I., Walker, J. M., \& Yellon, D. M. (2017). Anthracycline Chemotherapy and Cardiotoxicity. Cardiovascular drugs and therapy, 31(1), 63-75. doi:10.1007/s10557-016-6711-0

5. Bybee, K. A., \& Prasad, A. (2008). Stress-Related Cardiomyopathy Syndromes. Circulation, 118(4), 397-409. doi: 10.1161/circulationaha.106.677625

6. Asnani, A. (2018). Cardiotoxicity of Immunotherapy: Incidence, Diagnosis, and Management. Current Oncology Reports, 20(44). Doi: 10.1007/s11912-0180690-1

7. Pasupathy, S., Tavella, R., Mcrae, S., \& Beltrame, J. F. (2015). Myocardial Infarction With Non-obstructive Coronary Arteries - Diagnosis and Management. European Cardiology Review, 10(2), 79. doi: 10.15420/ ecr.2015.10.2.79 